\title{
Learning lessons from operational research in infectious diseases: can the same model be used for noncommunicable diseases in developing countries?
}

\author{
This article was published in the following Dove Press journal: \\ Advances in Medical Education and Practice \\ 4 December 2014 \\ Number of times this article has been viewed
}

\section{William K Bosu}

Department of Epidemics and Disease Control, West African Health Organisation, Bobo-Dioulasso, Burkina Faso

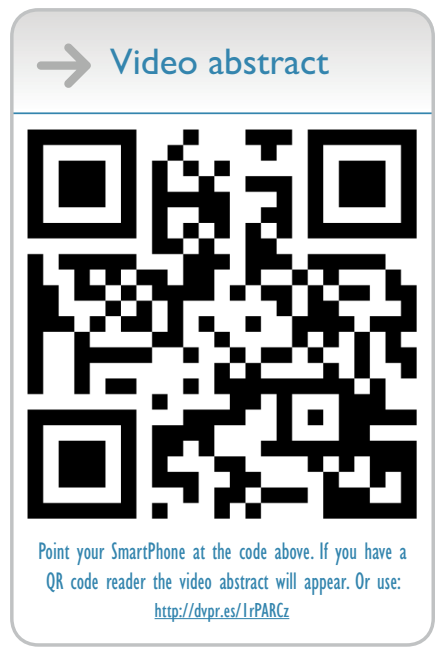

Correspondence: William K Bosu Department of Epidemics and Disease Control, West African Health Organisation, 175 Ouzzein Coulibaly Avenue, Bobo-Dioulasso 0I BP I53, Burkina Faso

Email wbosu@wahooas.org
Abstract: About three-quarters of global deaths from noncommunicable diseases (NCDs) occur in developing countries. Nearly a third of these deaths occur before the age of 60 years. These deaths are projected to increase, fueled by such factors as urbanization, nutrition transition, lifestyle changes, and aging. Despite this burden, there is a paucity of research on NCDs, due to the higher priority given to infectious disease research. Less than $10 \%$ of research on cardiovascular diseases comes from developing countries. This paper assesses what lessons from operational research on infectious diseases could be applied to NCDs. The lessons are drawn from the priority setting for research, integration of research into programs and routine service delivery, the use of routine data, rapid-assessment survey methods, modeling, chemoprophylaxis, and the translational process of findings into policy and practice. With the lines between infectious diseases and NCDs becoming blurred, it is justifiable to integrate the programs for the two disease groups wherever possible, eg, screening for diabetes in tuberculosis. Applying these lessons will require increased political will, research capacity, ownership, use of local expertise, and research funding.

Keywords: infectious diseases, noncommunicable diseases, operational research, developing countries, integration

\section{Introduction}

According to the Global Burden of Disease Study, the proportion of all deaths attributable to noncommunicable diseases (NCDs) in developing countries increased from $47.5 \%$ in 1990 to $58.3 \%$ in $2010 .{ }^{1}$ Similarly, the proportion of all disability-adjusted life-years (DALYs) lost attributable to NCDs increased from $36.4 \%$ to $48.6 \%$ over the same period. The burden varies between and within regions of the developing world. In the Eastern Caribbean region, 70\% of years of life lost are due to NCDs. ${ }^{2}$ In Brazil, $72 \%$ of all deaths were attributable to NCDs in $2007 .^{3}$

Developing countries face peculiar challenges relating to the epidemiology and control of NCDs. Cardiovascular disease (CVD)-related deaths occur 20 years earlier than in developed countries. ${ }^{4}$ They have a larger share of cancers of infectious disease etiology than developed countries $(22.9 \%$ versus $7.4 \%) .{ }^{5}$ Chagas disease as a cause of cardiomyopathy occurs predominantly in Latin America. The huge burden of NCDs of infectious origin is blurring the traditional division of diseases into communicable diseases and NCDs, and has to led to calls for integration of interventions. ${ }^{67}$ The relationship between tuberculosis (TB) and diabetes and its 
comorbidity with other NCDs has been well documented. ${ }^{8,9}$ The increasing use of highly active antiretroviral treatment (HAART) may be associated with an increased risk of CVDs. ${ }^{10}$

Unlike developed economies, there is low awareness of the risk factors for NCDs, even among health workers in developing countries. There is consequently late reporting when diseases have advanced, recourse to plant and homeopathic medicines, and generally poor outcomes. Up to $80 \%$ of hypertension or diabetes may be undiagnosed. ${ }^{11-13}$ Target-organ damage resulting from long-standing hypertension is relatively common. ${ }^{14}$ Cancers are typically diagnosed at their advanced stages. ${ }^{15}$

The financial burden on the fragile health systems of developing countries is enormous. Owing to their chronic course, incurability, and general high cost of treatment, NCDs are able to tip households into poverty or to maintain them in poverty. The impact on households is worst on vulnerable households in whom $30 \%-50 \%$ of their household incomes may be spent on chronic illnesses. ${ }^{16}$ In India, households containing a member with CVD spent 2.5 times as much of their total out-of-pocket expenditure on health care as that of socioeconomically and demographically matched control households (27.2\% versus $10.7 \%, P<0.01) .{ }^{17}$

The health systems of developing countries are oriented toward acute illnesses and not chronic illnesses. ${ }^{18}$ Many countries do not have NCD policies that sufficiently address the major risk factors. ${ }^{19}$ With continuing globalization, urbanization, aging, and nutrition transition, NCDs are projected to increase in developing countries in the coming decades. ${ }^{20}$ There is now a rapid growth of food and beverage industries, aggressive advertising, and weak regulation, all of which have contributed to the consumption of sugarsweetened beverages from an early age. ${ }^{21}$ The consumption of dietary salt exceeds the World Health Organization (WHO)-recommended levels in many developing countries. ${ }^{22}$ Tobacco and alcohol products are also increasingly being marketed in developing countries. ${ }^{23}$

In response to the growing threat from NCDs, there have been several regional and international initiatives. The most notable recent initiative was the United Nations (UN) General Assembly Political Declaration on the Prevention and Control of NCDs in September 2011. The high-level UN meeting has served to raise the profile of NCDs as a developmental issue, as they undermine the attainment of the Millennium Development Goals by 2015. ${ }^{24}$ There are continuing discussions on country actions and reforms needed to meet the UN commitments on NCDs..$^{25,26}$
The political declaration calls for investments in research and development related to improving the prevention and control of NCDs. ${ }^{24}$ Priority areas include improving program performance, health promotion, surveillance, cost-effectiveness, and sustainable interventions, as well as sharing of best practices and lessons learned. The WHO Global Plan Action 2013-2020 also specifies the promotion and development of national capacity for research as one of its six principal objectives. ${ }^{27}$ The World Health Report 2013, with its theme "Research for universal health coverage", argues for evidence-based actions to ensure affordable and quality health services that are accessible to all of a country's population. $^{28}$

Despite the growing burden of NCDs in developing countries and the importance of research in defining and monitoring their control, research output has been low. In line with the UN political declaration, this paper describes the research output on NCDs from developing countries and the impact of infectious disease in these countries, and examines some experiences from operational research on infectious diseases that could be applied to NCDs. It focuses on the four major NCDs covered by the declaration: CVDs, cancers, chronic respiratory diseases, and diabetes.

\section{Research output on NCDs in developing countries}

The volume of research in developing countries on NCDs is very low, likely a reflection of the huge researchfunding gap between developed and developing countries. Of 86,711 articles on CVD research published between 1995 and 2002 globally and available from the PubMed database, $90.5 \%$ were from Western Europe, the US, Japan, and Canada. ${ }^{29}$ Latin America and the Caribbean accounted for $1.1 \%$ of the articles, while Africa accounted for a lowly $0.3 \%$. Mendis et al observed that $78 \%-79 \%$ of CVD publications in 1991, 1996, and 2001 came from developed market economies, $6 \%-8 \%$ from developing countries, and 4\%-8\% from developing Eastern European countries. ${ }^{30}$ It is striking that there were no publications on CVDs from 82 developing countries in any of those years. More recently, of the $3 \%-4 \%$ of CVD papers that focused on at least one of the $20 \mathrm{WHO}$ NCD priority-research areas, $23 \%$ came from low- and middle-income countries. ${ }^{31}$ The share of papers in the WHO priority areas from low-income countries increased from $0 \%$ to $2 \%$ from 2002 to 2011, while that from middle-income countries increased from $10 \%$ to $21 \%$ over the same period.

A major reason for the low research output on NCDs from developing countries is low funding. Research output 
correlates well with gross domestic product per capita and with health expenditure per capita. ${ }^{29,32,33}$ Between 2004 and 2007 , the proportion of the overall development assistance for health allocated to NCDs increased from $1.5 \%$ to $2.3 \%$, while that for human immunodeficiency virus (HIV), TB, and malaria increased from $20.1 \%$ to $28.7 \% .{ }^{34}$ Donor funding amounted to only US\&78 for each DALY due to NCDs in 2008 compared with $\$ 23.9$ each DALY due to HIV, TB, and malaria. Without adequate funding, it is not surprising that publications on NCD research in developing countries are limited. ${ }^{33}$ Other reasons for low research output, such as low research capacity and limited training opportunities, are discussed later.

\section{Impact of infectious disease research on health}

The impact of health research and development on the control of infectious diseases has been enormous. It has provided the tools for the production of medicines, vaccines, and technology that have contributed improved survival of humanity. After the eradication of smallpox, the world is now on the brink of eradicating poliomyelitis and guinea-worm disease. Preventive chemotherapy neglected tropical diseases (NTDs), including onchocerciasis, lymphatic filariasis, and trachoma, and other NTDs, such as leprosy, have been targeted for elimination. Much progress has also been achieved with other poverty-associated NTDs, such as yaws and Buruli ulcer. Tremendous progress has also been made with the prevention and control of immunizable diseases, such as measles, diphtheria, whooping cough, and tetanus. Progress with the elimination of measles continues: its ranking as a cause of death in developing countries dropped from 16th to 53rd between 1990 and 2010. ${ }^{1}$ Conjugate vaccines have been developed that have now permitted vaccines against meningitis and pneumonia to be included in childhood immunization schedules.

Besides vaccines, improved drug treatment has contributed to the prevention and control of three of the major causes of disease burden in developing countries: malaria, TB, and HIV. ${ }^{35}$ Buoyed by the success of HAART, the Joint United Nations Programme on HIV/Acquired Immunodeficiency Syndrome (AIDS) has launched a campaign of zero new infections and zero AIDS-related deaths by $2015 .{ }^{36}$ The impact of these achievements transcends the spread of disease to other persons. It has benefits for NCDs and improved maternal and child health and nutrition, as well as socioeconomic benefits.

It is noteworthy that the impact of health research on infectious diseases is not merely attributable to the drugs or vaccines. It is through operational research that the effectiveness of the products under real-world settings are evaluated and their acceptability and best methods of delivery determined. Zachariah et al define operational research in terms of "knowledge on interventions, strategies, or tools that can enhance the quality, effectiveness, or coverage of programmes". ${ }^{37}$ Operational research has helped to influence practice and policy for several infectious diseases. Examples include the SAFE (Surgery [for trichiasis]-Antibiotics-Facial cleanliness-Environmental improvement) strategy for trachoma, ${ }^{38}$ expanding coverage of HAART, ${ }^{39-41}$ evaluating pre-HAART, ${ }^{42}$ evaluating surveillance for malaria elimination, ${ }^{43}$ improving the management of HIV-TB coinfection, ${ }^{44}$ evaluating cotrimoxazole preventive therapy, ${ }^{45}$ improving the diagnosis and management of recurrent $\mathrm{TB},{ }^{46}$ preventing mother-to-child transmission of $\mathrm{HIV}^{47}$ and the preventive treatment of malaria in infants. ${ }^{48}$ In their paper on the concepts, contributions, and challenges on operational research, Zachariah et al provide 16 examples of how it has improved medical care and practice, been used to assess the feasibility of interventions, and been used to advocate policy change. ${ }^{37}$

The application of operational research to derive the most impact from infectious diseases has not been fortuitous, but has been systematic. In the example of malaria control, a number of randomized controlled trials were conducted in Africa in the mid-1990s to establish the efficacy of insecticide-treated nets (ITNs) and materials for preventing malaria in children and pregnant women. ${ }^{49-53}$ A Cochrane systematic review concluded that ITNs reduced malaria-related mortality by $17 \%$ and morbidity by $34 \%$ when compared with untreated nets. ${ }^{54}$ The impact of ITNs was then tested in effectiveness studies in which the settings were less controlled and the ITNs had to be purchased. Further studies assessed whether the protective effects of ITNs were sustained in the long term. ${ }^{55}$ The cost-effectiveness of ITNs compared with other malaria-control interventions was also assessed. ${ }^{56-59}$ Operational research also examined operational issues in the delivery of the ITNs ${ }^{60}$ and factors influencing acceptability and use of the ITNs. ${ }^{61-63}$

Within a few years of the initial trial results, ITNs were introduced into malaria-control programs throughout Africa. ${ }^{64}$ Delivery mechanisms evolved to include mass distribution, sometimes as part of supplementary immunization campaigns. ${ }^{65}$ Operational research was conducted to answer implementation issues on both the demand and supply sides ${ }^{66,67}$ Free ITNs given to pregnant women during antenatal care in Kinshasa resulted in increased usage from $25 \%$ 
at baseline to $80 \%$ at 6 months postdelivery. ${ }^{68}$ In Tanzania, the implementation of a national voucher program for ITNs led to increased ownership and use of the ITNs. Questions on the availability and use of ITNs were incorporated into demographic and health surveys ${ }^{69}$ Local production of ITNs was established to assure sustainability. ${ }^{70}$ More recently, continued monitoring has led to a suspicion that the introduction of ITNs has been associated with insecticide resistance of the parasite and a waning of the immunity of children against malaria. ${ }^{71}$

A similar systematic approach could be described for the prevention of mother-to-child transmission of HIV, scaling up of antiretroviral therapy, directly observed therapy of TB, or the intermittent preventive treatment of malaria.

\section{Cross-cutting challenges on operational research in developing countries}

The capacity for health research in developing countries is weak across all the major disease groups: infectious diseases, communicable diseases, and injuries. ${ }^{72}$ A recent review identified such barriers as poorly equipped facilities, weak referral and follow-up systems, limited geographical access to services, limited knowledge and skills of health workers, weak health information systems, poor availability of drugs, and high service charges as hindering the management and delivery of NCD services in the Asia-Pacific region. ${ }^{18}$

Ethical review processes in developing countries often do not meet international standards. For instance, only $38 \%$ of 64 research-ethics committees in developing countries had their own annual budget. ${ }^{73}$ The committees who received an annual budget were significantly more likely to have a policy to check on conflicts of interest among their members and to organize continuing education.

Besides capacity, another overarching critical factor for operational research on all disease types is an enabling legislative or policy framework. A recent review of health research systems in 44 countries of the WHO African region found that only $30 \%$ had a national health research policy and $20 \%$ had a strategic plan. ${ }^{74}$ The research policy will usually address such issues as situation analysis, strategic vision for health research, guiding principles, priority setting, structural arrangements and relationships, capacity building, production, dissemination and utilization, ethical review, intellectual property, resource mobilization, and monitoring and evaluation. It should be aligned with overall health policy and respond to the prevailing health problems in the country. It should be dynamic and respond to new trends in research, including genetics and stem cell research. There is need for a lead health research institution and a national coordinating mechanism to plan, coordinate, and monitor the overall implementation of research activities. The governance structure is crucial to the planning of periodic national forums for priority setting and dissemination of research findings. Of the countries of the WHO African region, only a fifth have functional national health research management forums. ${ }^{74}$

\section{Potential lessons to be learned from operational infectious disease research}

Against the background of the challenges of conducting and managing research, there are some important lessons that could potentially be learned from the experiences from operational research on infectious diseases. Developing countries have had a longer and deeper experience with infectious diseases. These lessons relate to priority setting, survey methods, data sources, measurements, funding, and management. While the lessons are drawn from infectious diseases, several of the approaches are common to both disease groups and are not necessarily linear.

\section{Setting priorities}

There are guidelines on the process and the value of priority setting for health research in developing countries. ${ }^{75}$ A very useful checklist on the process for setting health research priorities is also available. ${ }^{76}$ It outlines what activities and factors should be considered in the preparatory stage, how priorities could be decided on, and what actions follow after priorities have been set. Priorities should be guided by the public health benefit and the cost and feasibility of implementation. They could be identified using consensus-based approaches and/or metric-based approaches. In Nigeria, a wide consultation involving policy makers and stakeholders at the state level was adopted to develop health research priorities using the essential national health research framework of the Council on Health Research for Development (COHRED). ${ }^{77}$ In East Timor, health research priorities were determined through an analysis of published and unpublished studies between 2001 and $2011 .^{78}$

The Child Health and Nutrition Research Initiative is an example of a metric-based approach that is increasingly being used in the developing country context. ${ }^{79}$ It uses a scientific, systematic, and transparent scoring system to assess various research options in terms of their potential 
answerability, potential to produce effective health interventions, potential for the intervention to be affordable and sustainable, and potential for the study to reduce disease burden and inequities.

Whatever the process, it is important to have a clearly articulated set of research priorities. Operational research priorities have been defined for such infectious diseases as guinea-worm disease,${ }^{80}$ helminthiasis, ${ }^{81} \mathrm{NTDs},{ }^{82} \mathrm{~TB},{ }^{83,84}$ malaria, ${ }^{85}$ and HIV control. ${ }^{86}$ The research priorities for NCDs should define the scope of what diseases a country considers NCDs. In developing countries, the focus on the four major NCDs (CVDs, diabetes, cancers, and chronic respiratory infections) and the four major risk factors (diet, physical activity, tobacco, alcohol) will enable their research programs to be better aligned to the WHO Global Action Plan 2013-2020 and the global target of 25\% reduction in premature NCD mortality by $2025 .{ }^{87}$

The WHO has published a priority-research agenda on CVDs with a focus on developing countries after a series of consultations between 2008 and $2010 .{ }^{88}$ The objectives of the agenda are to promote evidence-led decisions and actions to tackle NCDs, identify the knowledge gaps for which research is needed, and to strengthen NCD research capacity in developing countries. The agenda includes studies on the burden and social costs of CVD and other NCDs, social determinants of behavioral influences on NCDs, approaches to early detection, economic evaluation of models of combination of intervention, feasible and cost-effective methods of delivery of interventions for primary and secondary prevention of CVD, fixed-dose combination preventive and curative therapy, and the development and deployment of safer and affordable vaccines and drugs, particularly those against rheumatic heart disease and Chagas disease.

In November 2011, the Consortium for NCD Prevention and Control in Sub-Saharan Africa, with the support of the International Development Research Centre (IDRC), held a consultative meeting to develop a priority NCD research and capacity-building agenda in Africa. ${ }^{89}$ The priority-research issues were similar to those developed by the WHO. The agenda included epidemiological studies on the magnitude, patterns, and trends of disease, analysis of the determinants and social inequities, delivery of interventions, and the evaluation of their impact. It also specified studies to draw lessons from communicable diseases that could be applied to NCDs.

Besides the global and regional efforts, individual countries have identified research priorities for NCDs, the specific diseases, or their risk factors. ${ }^{90}$ For example, India has assessed its priorities on cancer research. ${ }^{91}$ As these priorities are defined more closely to the service-delivery or program-implementation level, they are more likely to reflect local needs.

The important lesson here is that a set of research priorities for NCDs should be defined within the framework of a national health research policy or plan. This process should be transparent, and consultations should be wide and include program managers and researchers on communicable diseases. In the light of the biological and epidemiological link between diabetes and TB, ${ }^{92}$ questions have been asked about the value of routinely screening TB patients for diabetes. ${ }^{93}$ Questions have also been asked about how the application of the widely successful DOTS (directly observed therapy, short course) could be of benefit to chronic NCDs. ${ }^{94}$ In Brazil, analysis of nationwide data showed that HIVinfected persons were significantly more likely to die from NCDs than non-HIV-infected persons. ${ }^{95}$ These reports of association between infectious diseases and NCDs illustrate the importance of involving stakeholders from both disease groups in order to develop NCD research priorities.

\section{Integration of operational research into programs}

The National TB Program (NTP) of Malawi is a remarkable example of how the integration of operational research into programs between 1996 and 2005 led to the prolific production of publications. ${ }^{96}$ The facilitating factors were the use of TB registers that captured clinical data including outcomes for cohorts of patients, regular clinical audit of these patients, monitoring of TB-HIV coinfections, and the appointment of a full-time operational research officer and a data manager. ${ }^{97}$ Problems and knowledge gaps identified during the implementation of the program activities were evaluated for research. This meant that the findings had direct and quicker application to the improvement of program performance and clinical practice.

The analysis of data obtained from routine reporting forms and registers to answer program-related questions and the subsequent publication of findings in peer-reviewed journals was thought to have inspired the health workers. ${ }^{97}$ This approach does not mean that research produced by academic and research institutions is not relevant. On the contrary, in order to improve its value in influencing practice or policy, it is essential that at the national or local level, a win-win partnership should be formed to conduct the operational research. The academic institutions will tend to have the research know-how, whereas 
it is the health workers who are responsible for service delivery and collecting routine data from which research questions could emerge. The NTP of Malawi organized annual scientific meetings during which research findings were presented and discussed.

Motivated by the desire to evaluate interventions in reallife settings, academics have integrated a cluster-randomized trial comparing strategies for HIV care into routine health care delivery in Uganda. ${ }^{98}$ Access to adequate funding and the availability of research capacity are crucial prerequisites to integrating operational research into programs. The NTP has the unique advantage of being vertically run with its own set of data-collection forms, registers, and laboratory forms and reporting primarily to the NTP rather than to the National Health Records Office. Further, the NTP has very good control of anti-TB drugs, as these drugs are used almost exclusively for TB and are provided free of charge. In contrast, the drugs for NCDs are not controlled by the NCD Control Program. While there could be disease-specific registers, such as those for diabetes or hypertension, these are usually managed at the hospital level and reports sent to the National Health Records Office.

Despite these limitations, NCD programs can still learn some lessons from infectious disease-control programs. For example, disease registers could be designed to collect information on family history, behavioral risk factors such as smoking, and practice of self-monitoring of glycemia. NCD control programs in developing countries therefore could pay more attention and integrate operational research into service delivery and program management.

\section{Use of routine data}

Routine data have been used for operational research to evaluate HIV testing and treatment among TB patients and to scale up anti-retroviral therapy (ART) ${ }^{99}$ Routine data have the advantages of being relatively easy to collect, cheaper, and easily adaptable. They have often been commonly used in the hospital settings to report case series, treatment outcomes, and cost studies. The main disadvantage is that when applied to patients in hospital settings, they may not be representative of the population from which the cases are drawn. Further, health workers are often overburdened, and so there are a limited number of variables on which data can be routinely collected on.

Cancer-registration systems use routine data collected in a systematic manner, usually in centers that have histopathologists or radio-oncology services. Routine data have been used to estimate the prevalence of hypertension in workers or other defined population groups, ${ }^{100}$ or to assess outcomes in a cohort of diabetic patients in primary health care settings after a 3-year follow-up. ${ }^{101}$

The choice of study designs in operational research depends on the study objective. These methods include descriptive and analytical studies, experimental design, and mathematical modeling. ${ }^{102}$ Owing to the limitations of routine data, such surveys as WHO STEPS, the Global Youth Tobacco Survey, and Global school-based health surveys are frequently used to estimate the prevalence of NCDs and monitor the major risk factors.

\section{Rapid survey methods and analytical tools}

Rapid tools for estimating the prevalence of infectious diseases are readily available for a number of infectious diseases. Rapid epidemiological mapping of onchocerciasis for mapping the prevalence and distribution has been widely used in the onchocerciasis-elimination program over the past 20 years. ${ }^{103,104}$ Onchocerciasis is identified through simple palpation in adult males for nodules. Rapid methods have been or are also being developed for the assessment of schistosomiasis, trachoma, and other preventive chemotherapy NTDs. ${ }^{105}$ Rapid-assessment procedures for loiasis, a rapidassessment tool for the mapping of loiasis, has been used in combination with rapid assessment of onchocerciasis. ${ }^{106}$ Outside of NTDs, another rapid-assessment tool is the Expanded Program of Immunization cluster survey, which was developed to estimate the coverage of immunization through the sampling of seven children aged 12-23 months in each of 30 clusters. ${ }^{107}$

Rapid-assessment tools depend on a reduced geographical area, a specified age-group, or the use of rapid diagnostic methods to rapidly assess the occurrence of disease or a condition and its distribution. The samples used in a rapid assessment may not be probability samples, but are designed to yield reliable information of programmatic value when conducted in a systematic way over time. The rapid surveys often combine interviews and examination of persons. For NCDs, rapid-assessment tools are generally lacking. One available tool is Rapid Assessment of Avoidable Blindness, used to assess the prevalence and causes of blindness and visual impairment. ${ }^{108}$

Besides the need for rapid epidemiological methods, operational research on NCDs could also benefit from rapid data collection and analysis. One example of such a tool is the electronically based STEPS survey or eSTEPS developed by the WHO, used for risk-factor survey of NCDs. ${ }^{109}$ It involves the use of personal digital assistants with a suite of software 
for data collection, data-quality checks, and tools for data analysis. The use of eSTEPS not only enables rapid data collection and analysis or the transport of fewer materials but also allows higher-quality data and standardization across studies in different sites.

\section{Rapid diagnostic methods}

Rapid tests are being continually developed for the diagnosis of malaria, TB, and HIV. The use of noninvasive samples, such as saliva and urine, has made a tremendous impact on homebased testing and on integrated biobehavioral surveillance of $\mathrm{HIV}$ in the general population and high-risk groups. ${ }^{110,111}$ One has to struggle to find similar high-impact rapid diagnostic tests for NCDs. One such test is the visual inspection of the cervix after application of acetic acid (VIA) or Lugol's iodine. The color change in the squamocolumnar epithelial junction of the cervix correlates with precursor changes that could lead to cervical cancer. VIA requires relatively inexpensive equipment, and can be performed by nonphysicians. These attributes have made it an attractive option for cervical cancer screening in developing countries. ${ }^{112}$ There are very promising prospects for the more superior simple rapid tests based on human papilloma virus (HPV) deoxyribonucleic acid tests, as these have already been used in rural areas in developing countries. ${ }^{13}$ The use of self-sampling is an added advantage for improving access to cervical cancer screening. ${ }^{114}$

Home-based test kits are available for the diagnosis of HIV. With regard to NCDs, home-based electronic devices are available for measuring blood levels of glucose, cholesterol, and triglycerides. Urine test strips can be used to diagnose urinary tract infections and biochemical abnormalities (ketones, protein, sugar). There are also electronic monitors for monitoring blood pressure. Patient self-monitoring is an essential part of the management of hypertension and diabetes. It is the availability of these home-based tests that makes it easier to assess risk factors or NCDs during field surveys. The disadvantage of these electronic devices is their high cost, which precludes their wide use in developing countries. The device for home blood-pressure monitoring, for example, costs \$80-\$100. However, it is believed that home blood-pressure monitoring could be potentially cost-saving in the long term, due to its advantages in detecting white-coat hypertension, improving treatment compliance, and reducing medication. ${ }^{115,116}$

Algorithms are widely used in the diagnosis and management of several infectious diseases, such as malaria, sexually transmitted infections, TB, and HIV. One advantage of the use of algorithms is that they can be tailored to a variety of health care-delivery settings. For example, the actions to be taken in the management of sexually transmitted infection syndromes depend on the availability of laboratory services. With respect to NCDs, at least 19 algorithms have been developed for the diagnosis and management of various conditions in the WHO Package of Essential Noncommunicable Disease Interventions for Primary Health Care in Low-Resource Settings. ${ }^{117}$

\section{Chemoprophylaxis}

The principle of chemoprophylaxis for primary or secondary prevention of infectious diseases is well known. It aims to prevent infection or disease when a person comes into contact with the infectious disease agent. Immunoglobulins are given when a person is suspected to have been exposed to the tetanus toxin or to the rabies virus. Postexposure prophylaxis with antiretroviral drugs is given to persons exposed to HIV through injury or sex. Penicillin V prophylaxis is a long-standing method of protecting patients with sickle-cell anemia from pneumococcal infection or those with rheumatic heart disease from disease when undergoing intestinal surgery or dental procedures. Cotrimoxazole preventive prophylaxis therapy provided to persons with symptomatic HIV and intermittent preventive therapy for malaria in pregnancy and infants are other examples of chemoprophylaxis. ${ }^{118}$

The use of chemoprophylaxis in NCDs is less common. Examples include prophylactic HPV vaccination, prophylactic mastectomy, ${ }^{119}$ and chemoprophylaxis in high-risk persons to prevent breast cancer. ${ }^{120}$ Statins and fixed-dose combination therapy have been evaluated for the primary prevention of CVDs. ${ }^{121-123}$ Several drugs have been shown to prevent or delay the occurrence of diabetes in high-risk persons. ${ }^{124}$ Drugs such as statins and aspirin have been more commonly used for the secondary prevention of complications in those who already have CVD.

Operational research is needed in developing countries on chemoprophylaxis against NCDs. Although the effect of aspirin and statins in secondary prevention has long been known, they are underused in developing countries. ${ }^{125}$ For example, only $39 \%$ of eligible diabetic patients ${ }^{126}$ and $63 \%$ of hypertensive patients ${ }^{127}$ attending specialist clinics in Nigeria were on aspirin preventive treatment. Total cardiovascular risk assessment through the use of prediction charts rather than the management of single risk factors in resource-constrained settings could reduce unnecessary treatment and save drug costs by more than $50 \%{ }^{128}$ Operational research showed that only two of the three 
available cardiovascular risk-assessment scoring systems was appropriate for Malaysia. ${ }^{129}$ Based on the experiences of primary and secondary prevention of infectious diseases, there is a wide scope of operational research to improve both pharmacologic and nonpharmacologic prevention of NCDs.

\section{Modeling}

The intensity of global attention to HIV/AIDS is reflected in the speed with which such models as the AIDS Impact Model and Spectrum were developed to help estimate the prevalence of HIV in the general population based on surveillance of pregnant women attending prenatal clinics. These models have been used to predict the demographic impact of AIDS, or to estimate the number of persons needing treatment. ${ }^{130-132}$ The models are continually refined, and so Spectrum 2013 has been developed. ${ }^{133}$ Modeling techniques have also been used to estimate the number of new infections of HIV according to modes of transmission that occur in individual countries. ${ }^{134}$ In the onchocerciasis-control program, the ONCHOSIM model is used to explore transmission and to provide crucial information on the number of years it will take to achieve elimination. ${ }^{135}$ These examples on these two infectious diseases illustrate how modeling could provide pertinent program information.

The most popular examples of modeling in NCDs are probably the cardiovascular risk-prediction score and cancer incidence and survival models. ${ }^{136,137}$ Models have also been used to predict out-of-office blood pressure from clinic measurements, ${ }^{138}$ guide the choice of HPV vaccines, ${ }^{139}$ assess the effectiveness of population-wide and individual high-risk strategies to prevent diabetes, ${ }^{140}$ and to predict the occurrence and progression of chronic kidney disease. ${ }^{141}$ These models have generally been used in high-income settings. Developing countries would benefit from models that have ready application in clinical practice (such as the Framingham risk score) and program and policy decision making in NCD prevention and control. For example, at the national level, NCD-control program managers in developing countries might be interested in the impact of urbanization and the nutrition transition on obesity and cardiometabolic diseases. They might also be interested in the impact of low detection, treatment, and control rates of hypertension on cardiovascular health. Modeling could also help address some of the persistent controversies regarding cancer screening ${ }^{142}$ or diabetes care. ${ }^{143}$ The absence of data from developing countries to feed mathematical models is a common challenge.

\section{Process of translation from research to policy and practice}

As previously described for ITNs, the translation of randomized control trial findings to policy is a systematic and phased process. This is also the case with the introduction of new vaccines into the immunization schedule of countries. This approach is not exclusively used by infectious disease programs. A team of American and Ghanaian obstetricians conducted a study to assess the safety and acceptability of cervical cancer screening through VIA and cryotherapy at a single-visit approach at a regional hospital in Accra. ${ }^{144}$ On the provider side, the quality of the diagnostics of the service providers (senior midwives and public health nurses) were compared with that of their trainers. ${ }^{145}$ The findings from these studies were satisfactory and informed the establishment of other VIA centers, including one in a rural site about $30 \mathrm{~km}$ from Accra.

Similarly, the Program for Appropriate Technology in Health and its local partners conducted formative research in Uganda, Peru, Vietnam, and India between 2006 and 2010 on the health policy environment that would inform the introduction of HPV vaccine in schoolgirls. ${ }^{146}$ Subsequently, the team conducted studies on the delivery mechanisms and factors that would help achieve high coverage of all three doses of the HPV vaccine. ${ }^{147}$

The main lessons from these examples are the values of formative research, understanding local circumstances, cost, affordability, and equity, and a gradual scaling up in the introduction of new tools, products, policies, and practices in NCDs. The phased approach allows the customized design of effective programs to address pertinent NCDs. There is also the need for continuing surveillance and postmarket evaluation after the introduction of the policy or intervention.

\section{Facilitating factors and opportunities}

Ensuring successful implementation of lessons learned from infectious disease research for the benefit of NCD research requires good political will, increased capacity, ownership, integrated planning, and funding. There is some evidence of increased political support for research. In 2006, the governments of Ghana and Nigeria, with support from the WHO Special Programme for Research and Training in Tropical Diseases, organized a high-level ministerial meeting on strategies for maximizing the benefits of health research for public health and development in Africa. ${ }^{148}$ The then president 
of Ghana, John Kufuor, delivered the keynote address at this meeting. Political support is needed to keep health research high on the agenda on priority actions for national development. The UN Political Declaration on NCDs provides the framework for addressing the major NCDs. The cross-cutting principles of health system strengthening and whole-of-government response are necessary for the conduct of any research and utilization of its findings. In other words, the political and social environment should be created for health research.

McKee et al divide countries into four groups on the basis of political commitment and research capacity: high commitment/ low research, high commitment/moderate research, low commitment/low research, and low commitment/moderate research. ${ }^{149}$ They suggest that countries with high commitment and moderate research capacity could be supported to assist other countries in their region. Developing countries could benefit from training from international institutions and partnerships, such as the European and Developing Countries Clinical Trials Partnership, the Fogarty International Center's International Research Ethics Education and Curriculum Development, and the African Cancer Registry Network.

While north-south collaboration is necessary, governments, regional economic communities, and partners should encourage the development of local and regional capacity. In this regard, such local initiatives as the Initiative to Strengthen Health Research Capacity in Africa, developed by health researchers and research funders in 2007, are commendable. ${ }^{150}$ Another regional initiative involves the strengthening of the health research systems of four countries (Guinea-Bissau, Liberia, Mali, and Sierra Leone) under a COHRED-West African Health Organization (WAHO) partnership with funding from the IDRC. It involves "strengthening governance structures, improving capacities of research institutions and researchers, financing research for health and enhancing the dissemination and utilisation of research results". ${ }^{151}$ In order to facilitate networking on research among the Economic Community of West Africa member states, the West African Health Organization has established a web-based platform (West Africa HRWeb), which provides pertinent health systems research information, including governance, research policy, research priorities, key research groups, ongoing research projects, and financing. ${ }^{152}$ The West Africa Health Research Network has also instituted a 9-month internship to develop the research capacity of young scientists in the region. Ministries of health and funding agencies should recognize and utilize local and regional capacity in the training for and conduct of NCD research. ${ }^{153}$
The integration of NCD and infectious disease services presents a good opportunity for operational research of mutual benefit to be conducted. Examples of such services include the integration of cervical screening in HIV services, integrating smoking cessation in HIV care, screening persons on ART for CVDs and diabetes, integrating HIV and alcohol care, bidirectional screening of TB and diabetes, and leveraging HIV-testing campaigns for NCDs. ${ }^{93,154}$ Mass drug administration contributes to increased uptake of ITNs. ${ }^{155}$ Integration of services allows the efficient use of available resources for operational research on multiple diseases. Jaffar et al propose the scaling up of testing services for NCDs using the model of HIV service delivery. ${ }^{98}$ Besides integration, the lessons learned from the effective implementation of infectious diseases could be applied to NCDs. In Malawi, the successes of the NTP were applied to the management of persons attending a diabetic clinic. ${ }^{94}$ These included quarterly analysis of the cohort of registered diabetic patients, the delivery of health passports including the clinic record to be kept by patients, and the monitoring of defaulting patients.

Ensuring the successful application of lessons learned requires accurate records. The shift toward electronic records at the point of care in many developing countries will help to eliminate the tedious manual recording and analysis that already-overburdened health workers have to endure. Health research programs should take advantage of e-health and mobile health facilities to improve coverage, data quality, and monitoring. ${ }^{156}$ It is also essential to engage all stakeholders from the outset in priority-setting meetings, integration of operational research into programs, or dissemination meetings. ${ }^{97}$ Operational research has traditionally been regarded as inferior research, although that perception is changing with the publication of many research findings in high-impact peer-reviewed journals. This is of course attractive to donors for continued funding. The dilemma faced by researchers from developing countries is that the full-text papers in these high-impact journals are often not accessible to national or regional researchers, for whom the results would be particularly beneficial.

The lack of funding, particularly for NCD programs, has been a major limitation to the production of research papers on NCDs. Unlike infectious diseases that obtain some research funding from global institutions, such as the Global Fund to Fight AIDS, TB, and Malaria, the Special Programme for Research and Training in Tropical Diseases, the United States President's Emergency Fund for AIDS Relief, and the President's Malaria Initiative, NCDs do not generally enjoy such funding. NCDs therefore have to depend on global, multilateral, and bilateral institutions, such as the Wellcome 
Trust, World Diabetes Foundation, and IDRC for funding. There are calls for Western countries to provide financial support for operational research in developing countries. ${ }^{157}$ Developing countries should engage their governments and the private sector for support. In 2008, African ministers of health committed themselves to the COHRED recommendation that developing countries should allocate at least $2 \%$ of their national health expenditure and at least $5 \%$ of external aid for health projects and programs to health research. ${ }^{158}$ Partnerships and groups, such as the Programme for Action on Cancer Therapy, the Lancet NCD Action Group, and the Global Task Force on Expanded Access to Cancer Care and Control in Developing Countries, provide rich resources on NCDs that will be useful for operational research.

\section{Conclusion}

There is a paucity of research from developing countries in general and on NCDs in particular. Factors accounting for this include limited funding, higher priority being given to infectious diseases, and limited research capacity. It is therefore reasonable to explore what and how lessons from experiences in operational research on infectious diseases could be applied to NCDs. These lessons derive from setting research priorities, integration of research into NCD programs, use of routine data, use of rapid-assessment methods and modeling techniques, interventions such as chemoprophylaxis, and translational research processes. Successful implementation of lessons learned will require political will, increased funding, and clear plans.

\section{Acknowledgments}

I thank the editor for giving me the opportunity to present this paper. I would also like to thank Dr Jude Aidam for his comments on an early draft.

\section{Disclosure}

The author reports no conflicts of interest in this work.

\section{References}

1. Institute for Health Metrics and Evaluation. GBD Database. Seattle, Washington, USA: University of Washington; 2014 [updated September 15, 2014; cited August 30, 2014]; Available from: http://www.healthdata. org/search-gbd-data. Accessed August 30, 2014.

2. World Bank. The Growing Burden of Non-communicable Diseases in the Eastern Caribbean. Washington: World Bank; 2011.

3. Schmidt MI, Duncan BB, Azevedo e Silva G, et al. Chronic non-communicable diseases in Brazil: burden and current challenges. Lancet. 2011;377(9781):1949-1961.

4. Moran A, Forouzanfar M, Sampson U, Chugh S, Feigin V, Mensah G. The epidemiology of cardiovascular diseases in sub-Saharan Africa: the Global Burden of Diseases, Injuries and Risk Factors 2010 Study. Prog Cardiovasc Dis. 2013;56(3):234-239.
5. De Martel C, Ferlay J, Franceschi S, et al. Global burden of cancers attributable to infections in 2008: a review and synthetic analysis. Lancet Oncol. 2012;13(6):607-615.

6. Remais JV, Zeng G, Li G, Tian L, Engelgau MM. Convergence of non-communicable and infectious diseases in low- and middle-income countries. Int J Epidemiol. 2012;42(1):221-227.

7. Hotez PJ, Daar AS. The CNCDs and the NTDs: blurring the lines dividing noncommunicable and communicable chronic diseases. PLoS Negl Trop Dis. 2008;2(10):e312.

8. Marais BJ, Lönnroth K, Lawn SD, et al. Tuberculosis comorbidity with communicable and non-communicable diseases: integrating health services and control efforts. Lancet Infect Dis. 2013;13(5): 436-438.

9. Jeon CY, Harries AD, Baker MA, et al. Bi-directional screening for tuberculosis and diabetes: a systematic review. Trop Med Int Health. 2010;15(11):1300-1314.

10. Bavinger $\mathrm{C}$, Bendavid $\mathrm{E}$, Niehaus $\mathrm{K}$, et al. Risk of cardiovascular disease from antiretroviral therapy for HIV: a systematic review. PLoS One. 2013;8(3):e59551.

11. Kayima J, Wanyenze RK, Katamba A, Leontsini E, Nuwaha F. Hypertension awareness, treatment and control in Africa: a systematic review. BMC Cardiovasc Disord. 2013;13:54.

12. Ibrahim MM, Damasceno A. Hypertension in developing countries. Lancet. 2012;380(9841):611-619.

13. Beagley J, Guariguata L, Weil C, Motala AA. Global estimates of undiagnosed diabetes in adults. Diabetes Res Clin Pract. 2014;103(2): $150-160$.

14. Oladapo OO, Salako L, Sadiq L, Shoyinka K, Adedapo K, Falase AO. Target-organ damage and cardiovascular complications in hypertensive Nigerian Yoruba adults: a cross-sectional study. Cardiovasc J Afr. 2012;23(7):379-384.

15. Unger-Saldaña K. Challenges to the early diagnosis and treatment of breast cancer in developing countries. World J Clin Oncol. 2014;5(3):465-477.

16. Kankeu HT, Saksena P, Xu K, Evans DB. The financial burden from non-communicable diseases in low-and middle-income countries: a literature review. Health Res Policy Syst. 2013;11:31.

17. Karan A, Engelgau M, Mahal A. The household-level economic burden of heart disease in India. Trop Med Int Health. 2014;19(5):581-591.

18. Mannava P, Abdullah A, James C, Dodd R, Annear PL. Health systems and noncommunicable diseases in the Asia-Pacific region: a review of the published literature. Asia Pac J Public Health. Epub October 4, 2013.

19. Lachat C, Otchere S, Roberfroid D, et al. Diet and physical activity for the prevention of noncommunicable diseases in low-and middle-income countries: a systematic policy review. PLoS Med. 2013;10(6):e1001465

20. World Health Organization. Global Status Report on Noncommunicable Diseases 2010. Geneva: WHO; 2011.

21. Moodie R, Stuckler D, Monteiro C, et al. Profits and pandemics: prevention of harmful effects of tobacco, alcohol, and ultra-processed food and drink industries. Lancet. 2013;381(9867):670-679.

22. Powles J, Fahimi S, Micha R, et al. Global, regional and national sodium intakes in 1990 and 2010: a systematic analysis of $24 \mathrm{~h}$ urinary sodium excretion and dietary surveys worldwide. BMJ Open. 2013;3:e003733.

23. World Health Organization. The World Health Report: Reducing the Risks, Promoting Healthy Life. Geneva: WHO;2002.

24. United Nations General Assembly. Political Declaration of the HighLevel Meeting of the General Assembly on the Prevention and Control of Non-communicable Diseases. New York: UN; 2011.

25. Alleyne G, Binagwaho A, Haines A, et al. Embedding noncommunicable diseases in the post-2015 development agenda. Lancet. 2013;381(9866):566-574.

26. Mendis S, Chestnov O. Policy reform to realize the commitments of the political declaration on noncommunicable diseases. $\mathrm{Br}$ Med Bull. 2013;105(1):7-27. 
27. World Health Organization. Global Action Plan for the Prevention and Control of Noncommunicable Diseases 2013-2020. Geneva: WHO; 2013.

28. World Health Organization. World Health Report 2013: No Health Without Research. Geneva: WHO; 2013.

29. Rosmarakis ES, Vergidis PI, Soteriades ES, Paraschakis K, Papastamataki PA, Falagas ME. Estimates of global production in cardiovascular diseases research. Int J Cardiol. 2005;100(3):443-449.

30. Mendis S, Yach D, Bengoa R, Narvaez D, Zhang X. Research gap in cardiovascular disease in developing countries. Lancet. 2003;361(9376): 2246-2247.

31. Myers L, Mendis S. Cardiovascular disease research output in WHO priority areas between 2002 and 2011. J Epidemiol Glob Health. 2014;4(1):23-28.

32. Rodriguez-Granillo GA, Rodriguez AE, Bruining N, et al. Quantification of scientific output in cardiovascular medicine: a perspective based on global data. EuroIntervention. 2013;9(8):975-978.

33. Hofman K, Ryce A, Prudhomme W, Kotzin S. Reporting of noncommunicable disease research in low-and middle-income countries: a pilot bibliometric analysis. J Med Libr Assoc. 2006;94(4): 415-420.

34. Nugent R, Feigl AB. Where Have All the Donors Gone?: Scarce Donor Funding for Non-communicable Diseases. Washington: Center for Global Development; 2010.

35. Murray CJ, Ortblad KF, Guinovart C, et al. Global, regional, and national incidence and mortality for HIV, tuberculosis, and malaria during 1990-2013: a systematic analysis for the Global Burden of Disease Study 2013. Lancet. 2014;384(9947):1005-1070.

36. Joint United Nations Programme on HIV/AIDS. Getting to Zero 2011-2015 Strategy. Geneva: UNAIDS; 2013.

37. Zachariah R, Harries AD, Ishikawa N, et al. Operational research in low-income countries: what, why, and how? Lancet Infect Dis. 2009;9(11):711-717.

38. Emerson PM, Burton M, Solomon AW, Bailey R, Mabey D. The SAFE strategy for trachoma control: using operational research for policy, planning and implementation. Bull World Health Organ. 2006;84(8):613-619.

39. Mben JM, Kouanfack C, Essomba CN, et al. Operational research and HIV policy and guidelines: lessons from a study of patients lost to follow-up from a public antiretroviral treatment program in Cameroon. J Public Health Policy. 2012;33(4):462-477.

40. Harries AD, Makombe SD, Schouten EJ, et al. How operational research influenced the scale up of antiretroviral therapy in Malawi. Health Care Manag Sci. 2012;15(3):197-205.

41. Boyer S, Koulla-Shiro S, Abe C, Spire B, Moatti JP. Implementing operational research to scale-up access to antiretroviral therapy for HIV infection: lessons learned from the Cameroonian experience. Curr Opin HIV AIDS. 2011;6(4):239-244.

42. Burtle D, Welfare W, Elden S, et al. Introduction and evaluation of a 'pre-ART care' service in Swaziland: an operational research study. BMJ Open. 2012;2(2): $\mathrm{e} 000195$.

43. Atkinson JA, Johnson ML, Wijesinghe R, et al. Operational research to inform a sub-national surveillance intervention for malaria elimination in Solomon Islands. Malar J. 2012;11:101.

44. Sculier D, Getahun H, Lienhardt C. Improving the prevention, diagnosis and treatment of TB among people living with HIV: the role of operational research. J Int AIDS Soc. 2011;14 Suppl 1:S5.

45. Harries AD, Zachariah R, Chimzizi R, et al. Operational research in Malawi: making a difference with cotrimoxazole preventive therapy in patients with tuberculosis and HIV. BMC Public Health. 2011;11:593.

46. Harries A, Salaniponi F. Recurrent tuberculosis in Malawi: improved diagnosis and management following operational research. Trans $R$ Soc Trop Med Hyg. 2001;95(5):503-504.

47. Zvandasara P, Magwali T, Mulambo J, Sithole J. Acceptance of HIV screening in an antenatal population at a referral teaching hospital in Zimbabwe: a substudy of an operational research in prevention of mother to child HIV vertical transmission. Cent Afr J Med. 2005; 52(3-4):31-35.
48. Maokola W, Chemba M, Hamisi Y, et al. Safety of sulfadoxine/ pyrimethamine for intermittent preventive treatment of malaria in infants: evidence from large-scale operational research in southern Tanzania. Int Health. 2011;3(3):154-159.

49. Nevill C, Some E, Mung'Ala V, et al. Insecticide-treated bednets reduce mortality and severe morbidity from malaria among children on the Kenyan coast. Trop Med Int Health. 1996;1(2):139-146.

50. D'alessandro U, Olaleye B, Langerock P, et al. Mortality and morbidity from malaria in Gambian children after introduction of an impregnated bednet programme. Lancet. 1995;345(8948):479-483.

51. Binka FN, Kubaje A, Adjuik M, et al. Impact of permethrin impregnated bednets on child mortality in Kassena-Nankana district, Ghana: a randomized controlled trial. Trop Med Int Health. 1996;1(2):147-154.

52. Shulman C, Dorman E, Talisuna A, et al. A community randomized controlled trial of insecticide-treated bednets for the prevention of malaria and anaemia among primigravid women on the Kenyan coast. Trop Med Int Health. 1998;3(3):197-204.

53. Habluetzel A, Diallo D, Esposito F, et al. Do insecticide-treated curtains reduce all-cause child mortality in Burkina Faso? Trop Med Int Health. 1997;2(9):855-862.

54. Lengeler $C$. Insecticide-treated bed nets and curtains for preventing malaria. Cochrane Database Syst Rev. 2004;(2):CD000363.

55. Lindblade KA, Eisele TP, Gimnig JE, et al. Sustainability of reductions in malaria transmission and infant mortality in western Kenya with use of insecticide-treated bednets: 4 to 6 years of follow-up. JAMA. 2004;291(21):2571-2580.

56. Wiseman V, Hawley WA, Ter Kuile FO, et al. The cost-effectiveness of permethrin-treated bed nets in an area of intense malaria transmission in western Kenya. Am J Tro Med Hyg. 2003;68(Suppl 4):161-167.

57. Binka FN, Mensah OA, Mills A. The cost-effectiveness of permethrin impregnated bednets in preventing child mortality in Kassena-Nankana district of Northern Ghana. Health Policy. 1997;41(3):229-239.

58. Goodman C, Mnzava A, Dlamini S, Sharp B, Mthembu D, Gumede J. Comparison of the cost and cost-effectiveness of insecticide-treated bednets and residual house-spraying in KwaZulu-Natal, South Africa. Trop Med Int Health. 2001;6(4):280-295.

59. Guyatt HL, Corlett SK, Robinson TP, Ochola SA, Snow RW. Malaria prevention in highland Kenya: indoor residual house-spraying vs insecticide-treated bednets. Trop Med Int Health. 2002;7(4):298-303.

60. Snow R, McCabe E, Mbogo C, et al. The effect of delivery mechanisms on the uptake of bed net re-impregnation in Kilifi District, Kenya. Health Policy Plan. 1999;14(1):18-25.

61. Kachur SP, Phillips-Howard PA, Odhacha AM, Ruebush TK, Oloo AJ, Nahlen BL. Maintenance and sustained use of insecticide-treated bednets and curtains three years after a controlled trial in western Kenya. Trop Med Int Health. 1999;4(11):728-735.

62. Gyapong M, Gyapong JO, Amankwa J, Asedem J, Sory E. Introducing insecticide impregnated bednets in an area of low bednet usage: an exploratory study in north-east Ghana. Trop Med Int Health. 1996;1(3):328-333.

63. Binka F, Adongo P. Acceptability and use of insecticide impregnated bednets in northern Ghana. Trop Med Int Health. 1997;2(5):499-507.

64. Müller O, Cham K, Jaffar S, Greenwood B. The Gambian National Impregnated Bednet Programme: evaluation of the 1994 cost recovery trial. Soc Sci Med. 1997;44(12):1903-1909.

65. Wolkon A, Eng JLV, Morgah K, et al. Rapid scale-up of long-lasting insecticide-treated bed nets through integration into the national immunization program during child health week in Togo, 2004. Am J Trop Med Health. 2010;83(5):1014-1019.

66. Bennett A, Smith SJ, Yambasu S, et al. Household possession and use of insecticide-treated mosquito nets in Sierra Leone 6 months after a national mass-distribution campaign. PLoS One. 2012;7(5):e37927.

67. Hoffman SJ, Guindon GE, Lavis JN, et al. Assessing healthcare providers' knowledge and practices relating to insecticide-treated nets and the prevention of malaria in Ghana, Laos, Senegal and Tanzania. Malar J. 2011;10:363. 
68. Pettifor A, Taylor E, Nku D, et al. Free distribution of insecticide treated bed nets to pregnant women in Kinshasa: an effective way to achieve $80 \%$ use by women and their newborns. Trop Med Int Health. 2009;14(1):20-28.

69. Welch K, Fuster M. Barriers in access to insecticide-treated bednets for malaria prevention: an analysis of Cambodian DHS data. J Vector Borne Dis. 2012;49(1):1-7.

70. Rashed S, Johnson H, Dongier P, et al. Sustaining malaria prevention in Benin: local production of bednets. Health Policy Plan. 1997;12(1):67-76.

71. Trape J-F, Tall A, Diagne N, et al. Malaria morbidity and pyrethroid resistance after the introduction of insecticide-treated bednets and artemisinin-based combination therapies: a longitudinal study. Lancet Infect Dis. 2011;11(12):925-932.

72. Bennett S, Adam T, Zarowsky C, et al. From Mexico to Mali: progress in health policy and systems research. Lancet. 2008;372(9649): 1571-1578.

73. Silverman H, Sleem H, Moodley K, et al. Results of a self-assessment tool to assess the operational characteristics of research ethics committees in low- and middle-income countries. J M Ethics. Epub April 19, 2014.

74. Mbondji PE, Kebede D, Zielinski C, Kouvividila W, Sanou I, LusambaDikassa PS. Overview of national health research systems in subSaharan Africa: results of a questionnaire-based survey. J R Soc Med. 2014;107(Suppl 1):46-54.

75. Nuyens Y. Setting priorities for health research: lessons from lowand middle-income countries. Bull World Health Organ. 2007;85(4): 319-321.

76. Viergever RF, Olifson S, Ghaffar A, Terry RF. A checklist for health research priority setting: nine common themes of good practice. Health Res Policy Syst. 2010;8:36.

77. Uneke CJ, Ezeoha AE, Ndukwe CD, Oyibo PG, Onwe F, Aulakh BK. Research priority setting for health policy and health systems strengthening in Nigeria: the policymakers and stakeholders perspective and involvement. Pan Afr Med J. 2013;16:10.

78. Deen J, da Conceicao Matos L, Temple B, et al. Identifying national health research priorities in Timor-Leste through a scoping review of existing health data. Health Res Policy Syst. 2013;11:8.

79. Rudan I. Global health research priorities: mobilizing the developing world. Public Health. 2012;126(3):237-240.

80. Kumar A. Operational research need in guineaworm eradication programme. J Commun Dis. 1990;22(4):236-242.

81. Lustigman S, Prichard RK, Gazzinelli A, et al. A research agenda for helminth diseases of humans: the problem of helminthiases. PLoS Negl Trop Dis. 2012;6(4):e1582.

82. Dujardin J-C, Herrera S, Do Rosario V, et al. Research priorities for neglected infectious diseases in Latin America and the Caribbean region. PLoS Negl Trop Dis. 2010;4(10):e780.

83. Murray CJ. Social, economic and operational research on tuberculosis: recent studies and some priority questions. Bull Int Union Tuberc Lung Dis. 1991;66(4):149-156.

84. Marais BJ, Raviglione MC, Donald PR, et al. Scale-up of services and research priorities for diagnosis, management, and control of tuberculosis: a call to action. Lancet. 2010;375(9732):2179-2191.

85. Durrheim DN, Speare R, Harries AD. Research that influences policy and practice - characteristics of operational research to improve malaria control in Mpumalanga Province, South Africa. Malar J. 2002;1:9.

86. Boyd MA, Nwizu CA. Operational research in HIV priority areas: the African way. Lancet. 2010;376(9734):4-6.

87. Bonita R, Magnusson R, Bovet P, et al. Country actions to meet UN commitments on non-communicable diseases: a stepwise approach. Lancet. 2013;381(9866):575-584.

88. World Health Organization. A Prioritized Research Agenda for Prevention and Control of Noncommunicable Diseases. Geneva: WHO; 2011.

89. African Institute for Health and Development (AIHD). Proceedings of the Technical Meeting on Research and Capacity Building for NCDs in Eastern and Southern Africa; November 28-29, 2011; Nairobi, Kenya.
90. Duncan BB, Chor D, Aquino EM, et al. [Chronic non-communicable diseases in Brazil: priorities for disease management and research]. Rev Saude Publica. 2012;46 Suppl 1:126-134. Portuguese.

91. Sullivan R, Badwe RA, Rath GK, et al. Cancer research in India: national priorities, global results. Lancet Oncol. 2014;15(6):e213-e222.

92. Jeon CY, Murray MB. Diabetes mellitus increases the risk of active tuberculosis: a systematic review of 13 observational studies. PLoS Med. 2008;5(7):e152.

93. Harries AD, Billo N, Kapur A. Links between diabetes mellitus and tuberculosis: should we integrate screening and care? Trans $R$ Soc Trop Med Hyg. 2009;103(1):1-2.

94. Allain TJ, van Oosterhout JJ, Douglas GP, et al. Applying lessons learnt from the 'DOTS' tuberculosis model to monitoring and evaluating persons with diabetes mellitus in Blantyre, Malawi. Trop Med Int Health. 2011;16(9):1077-1084.

95. Paula AA, Schechter M, Tuboi SH, et al. Continuous increase of cardiovascular diseases, diabetes, and non-HIV related cancers as causes of death in HIV-infected individuals in Brazil: an analysis of nationwide data. PLoS One. 2014;9(4):e94636.

96. Harries A, Hargreaves N, Banda H, et al. Tuberculosis research in Malawi: making it count. Recent Adv Res Updat. 2001;2: 103-118.

97. Zachariah R, Ford N, Maher D, et al. Is operational research delivering the goods? The journey to success in low-income countries. Lancet Infect Dis. 2012;12(5):415-421.

98. Jaffar S, Amuron B, Birungi J, et al. Integrating research into routine service delivery in an antiretroviral treatment programme: lessons learnt from a cluster randomized trial comparing strategies of HIV care in Jinja, Uganda. Trop Med Int Health. 2008;13(6):795-800.

99. Harries AD, Zachariah R, Maher D. The power of data: using routinely collected data to improve public health programmes and patient outcomes in low- and middle-income countries. Trop Med Int Health. 2013;18(9):1154-1156.

100. Seck SM, Guéye S, Tamba K, Ba I. Prevalence of chronic cardiovascular and metabolic diseases in Senegalese workers: a cross-sectional study, 2010. Prev Chronic Dis. 2013;10:110339.

101. Khader A, Ballout G, Shahin Y, et al. Treatment outcomes in a cohort of Palestine refugees with diabetes mellitus followed through use of e-health over 3 years in Jordan. Trop Med Int Health. 2014;19(2): 219-223.

102. Remme JH, Adam T, Becerra-Posada F, et al. Defining research to improve health systems. PLoS Med. 2010;7(11):e1001000.

103. Ngoumou P, Walsh J. A Manual for Rapid Epidemiological Mapping of Onchocerciasis. Geneva: UNDP/World Bank/WHO Special Programme for Research and Training in Tropical Diseases; 1993.

104. Zouré HG, Noma M, Tekle AH, et al. The geographic distribution of onchocerciasis in the 20 participating countries of the African Programme for Onchocerciasis Control: (2) pre-control endemicity levels and estimated number infected. Parasit Vectors. 2014;7:326.

105. Brooker S, Kabatereine NB, Gyapong JO, Stothard JR, Utzinger J. Rapid mapping of schistosomiasis and other neglected tropical diseases in the context of integrated control programmes in Africa. Parasitology. 2009;136(13):1707-1718.

106. Wanji S, Tendongfor N, Esum M, Yundze SS, Taylor MJ, Enyong P. Combined utilisation of rapid assessment procedures for loiasis (RAPLOA) and onchocerciasis (REA) in rain forest villages of Cameroon. Filaria J. 2005;4(1):2.

107. Henderson RH, Sundaresan T. Cluster sampling to assess immunization coverage: a review of experience with a simplified sampling method. Bull World Health Organ. 1982;60(2):253-260.

108. Dineen B, Foster A, Faal H. A proposed rapid methodology to assess the prevalence and causes of blindness and visual impairment. Ophthalmic epidemiology. 2006;13(1):31-34.

109. World Health Organization. Chronic diseases and health promotion: eSTEPS. 2009. http://www.who.int/chp/steps/esteps/en. Accessed September 15, 2014. 
110. Brennan AT, Thea DM, Semrau K, et al. In-home HIV testing and nevirapine dosing by traditional birth attendants in rural Zambia: a feasibility study. J Midwifery Womens Health. 2014;59(2): 198-204.

111. Saidel T, Adhikary R, Mainkar M, et al. Baseline integrated behavioural and biological assessment among most at-risk populations in six high-prevalence states of India: design and implementation challenges. AIDS. 2008;22 Suppl 5:S17-S34.

112. Paul P, Winkler JL, Bartolini RM, et al. Screen-and-treat approach to cervical cancer prevention using visual inspection with acetic acid and cryotherapy: experiences, perceptions, and beliefs from demonstration projects in Peru, Uganda, and Vietnam. Oncologist. 2013;18(12):1278-1284

113. Gage JC, Ajenifuja KO, Wentzensen N, et al. Effectiveness of a simple rapid human papillomavirus DNA test in rural Nigeria. Int J Cancer. 2012;131(12):2903-2909.

114. Levinson KL, Abuelo C, Salmeron J, et al. The Peru Cervical Cancer Prevention Study (PERCAPS): the technology to make screening accessible. Gynecol Oncol. 2013;129(2):318-323.

115. Pickering TG, Miller NH, Ogedegbe G, et al. Call to action on use and reimbursement for home blood pressure monitoring: executive summary: a joint scientific statement from the American Heart Association, American Society Of Hypertension, and Preventive Cardiovascular Nurses Association. Hypertension. 2008;52(1):1-9.

116. Stergiou GS, Bliziotis IA. Home blood pressure monitoring in the diagnosis and treatment of hypertension: a systematic review. Am J Hypertens. 2011;24(2):123-134.

117. World Health Organization. Package of Essential Noncommunicable (PEN) Disease Interventions for Primary Health Care in Low-Resource Settings. Geneva: WHO; 2010.

118. Kayentao K, Garner P, Maria Van Eijk A, et al. Intermittent preventive therapy for malaria during pregnancy using 2 vs 3 or more doses of sulfadoxine-pyrimethamine and risk of low birth weight in Africa: systematic review and meta-analysis. JAMA. 2013;309(6): 594-604.

119. Lostumbo L, Carbine N, Wallace J, Ezzo J. Prophylactic mastectomy for the prevention of breast cancer. Cochrane Database Syst Rev. 2004;(4):CD002748.

120. Colditz GA, Bohlke K. Priorities for the primary prevention of breast cancer. CA Cancer J Clin. 2014;64(3):186-194.

121. Tonelli M, Lloyd A, Clement F, et al. Efficacy of statins for primary prevention in people at low cardiovascular risk: a meta-analysis. CMAJ. 2011;183(16):E1189-E1202.

122. de Cates AN, Farr MR, Wright N, et al. Fixed-dose combination therapy for the prevention of cardiovascular disease. Cochrane Database Syst Rev. April 16, 2014;4:CD009868.

123. Carey KM, Comee MR, Donovan JL, Kanaan AO. A polypill for all? Critical review of the polypill literature for primary prevention of cardiovascular disease and stroke. Ann Pharmacother. 2012;46(5) 688-695.

124. Anderson DC. Pharmacologic prevention or delay of type 2 diabetes mellitus. Ann Pharmacother. 2005;39(1):102-109.

125. Mendis S, Abegunde D, Yusuf S, et al. WHO study on Prevention of REcurrences of Myocardial Infarction and StrokE (WHO-PREMISE). Bull World Health Organ. 2005;83(11):820-829.

126. Kolawole B, Adebayo R, Aloba O. An assessment of aspirin use in a Nigerian diabetes outpatient clinic. Niger J Med. 2003;13(4): 405-406.

127. Olanrewaju T, Aderibigbe A, Chijioke A, et al. Descriptive analysis of blood pressure control among treated hypertensive patients in a tertiary hospital in Nigeria. Afr J Med Med Sci. 2011;40(3):207-212.

128. Mendis S, Lindholm LH, Anderson SG, et al. Total cardiovascular risk approach to improve efficiency of cardiovascular prevention in resource constrain settings. J Clin Epidemiol. 2011;64(12):1451-1462.

129. Selvarajah S, Kaur G, Haniff J, et al. Comparison of the Framingham Risk Score, SCORE and WHO/ISH cardiovascular risk prediction models in an Asian population. Int J Cardio. 2014;176(1):211-218.
130. Ghys PD, Brown T, Grassly N, et al. The UNAIDS Estimation and Projection Package: a software package to estimate and project national HIV epidemics. Sex Transm Infect. 2004;80 Suppl 1:i5-i9.

131. Stover J, Walker N, Grassly N, Marston M. Projecting the demographic impact of AIDS and the number of people in need of treatment: updates to the Spectrum projection package. Sex Transm Infect. 2006;82 Supp1 3: iii45-iii50.

132. Stover J. AIM: A Computer Program for Making HIV/AIDS Projections and Examining the Demographic and Social Impacts of AIDS. Washington: United States Agency for International Development; 2009.

133. Marsh K, Mahy M, Salomon JA, Hogan DR. Assessing and adjusting for differences between HIV prevalence estimates derived from national population-based surveys and antenatal care surveillance, with applications for Spectrum 2013. AIDS. Epub September 5, 2014.

134. Gouws E, Cuchi P. Focusing the HIV response through estimating the major modes of HIV transmission: a multi-country analysis. Sex Transm Infect. 2012;88 Suppl 2:i76-i85.

135. Plaisier A, Van Oortmarssen G, Habbema J, Remme J, Alley E. ONCHOSIM: a model and computer simulation program for the transmission and control of onchocerciasis. Comput Methods Programs Biomed. 1990;31(1):43-56.

136. Ferlay J, Soerjomataram I, Dikshit R, et al. Cancer incidence and mortality worldwide: sources, methods and major patterns in GLOBOCAN 2012. International Journal of Cancer. Epub September 13, 2014

137. Siontis G, Tzoulaki I, Siontis KC, Ioannidis J. Comparisons of established risk prediction models for cardiovascular disease: systematic review. BMJ. 2012;344:e3318.

138. Sheppard JP, Holder R, Nichols L, et al. Predicting out-of-office blood pressure level using repeated measurements in the clinic: an observational cohort study. J Hypertens. 2014;32(11):2171-2178.

139. Jit M, Demarteau N, Elbasha E, et al. Human papillomavirus vaccine introduction in low-income and middle-income countries: guidance on the use of cost-effectiveness models. BMC Med. 2011;9:54.

140. Manuel DG, Rosella LC, Tuna M, Bennett C, Stukel TA. Effectiveness of community-wide and individual high-risk strategies to prevent diabetes: a modelling study. PLoS One. 2013;8(1):e52963.

141. Echouffo-Tcheugui JB, Kengne AP. Risk models to predict chronic kidney disease and its progression: a systematic review. PLoS Med. 2012;9(11):e1001344.

142. Zervoudis S, Iatrakis G, Tomara E, Bothou A, Papadopoulos G, Tsakiris G. Main controversies in breast cancer. World J Clin Oncol. 2014;5(3):359-373.

143. Gajos G, Piłaciński S, Zozulińska-Ziółkiewicz D. Controversies in diabetes in 2013-a brief update. Adv Clin Exp Med. 2012;22(6) 777-784.

144. Blumenthal PD, Gaffikin L, Deganus S, Lewis R, Emerson M, Adadevoh S. Cervical cancer prevention: safety, acceptability, and feasibility of a single-visit approach in Accra, Ghana. Am J Obstet Gynecol. 2007;196(4):407. e1-e8; discussion 407. e8-e9.

145. Sanghvi H, Limpaphayom KK, Plotkin M, et al. Cervical cancer screening using visual inspection with acetic acid: operational experiences from Ghana and Thailand. Reprod Health Matters. 2008;16(32):67-77.

146. LaMontagne DS, Barge S, Thi Le N, et al. Human papillomavirus vaccine delivery strategies that achieved high coverage in low- and middle-income countries. Bull World Health Organ. 2011;89(11):821-830.

147. Tsu VD, Cernuschi T, LaMontagne DS. Lessons learned from HPV vaccine delivery in low-resource settings and opportunities for HIV prevention, treatment, and care among adolescents. J Acquir Immune Defic Syndr. 2014;66 Supp1 2:S209-S216.

148. Ministry of Health Ghana, Ministry of Health Nigeria, WHO TDR. Health Research for Disease Control and Development-Communiqué. Accra, Ghana: Ministry of Health; 2006.

149. McKee M, Stuckler D, Basu S. Where there is no health research: what can be done to fill the global gaps in health research? PLoS Med. 2012;9(4):e1001209. 
150. ISHReCA. Initiative to strengthen health research capacity in Africa. 2008. Available from: http://www.mrc.ac.za/researchdevelopment/ ISHReCAbrochure.pdf. Accessed September 14, 2014.

151. Council on Health Research and Development. Strengthening research system development for health in West Africa. 2013. Available from: http://www.cohred.org/westafrica. Accessed September 14, 2014.

152. West African Health Organisation. West Africa HRWeb. 2013. Available from: http://www.wahooas.org/spip.php?article512\&lang=en. Accessed September 14, 2014.

153. Simba D, Mukose A, Bazeyo W. Institutional capacity for health systems research in East and Central African Schools of Public Health: strengthening human and financial resources. Health Res Policy Syst. 2014;12:23.

154. Chamie G, Kwarisiima D, Clark TD, et al. Leveraging rapid community-based HIV testing campaigns for non-communicable diseases in rural Uganda. PLoS One. 2012;7(8):e43400.
155. Noblick J, Skolnik R, Hotez PJ. Linking global HIV/AIDS treatments with national programs for the control and elimination of the neglected tropical diseases. PLoS Negl Trop Dis. 2011;5(7):e1022.

156. Aranda-Jan CB, Mohutsiwa-Dibe N, Loukanova S. Systematic review on what works, what does not work and why of implementation of mobile health (mHealth) projects in Africa. BMC Public Health. 2014;14:188.

157. Quaglio G, Ramsay A, Harries AD, et al. Calling on Europe to support operational research in low-income and middle-income countries. Lancet Glob Health. 2014;2(6):e308-e310.

158. World Health Organization. The Algiers Declaration. Poster presented at: Ministerial Conference on Research for Health in the African Region; June 23-26, 2008; Algiers, Algeria.

\section{Publish your work in this journal}

Advances in Medical Education and Practice is an international, peerreviewed, open access journal that aims to present and publish research on Medical Education covering medical, dental, nursing and allied health care professional education. The journal covers undergraduate education, postgraduate training and continuing medical education including emerging trends and innovative models linking education, research, and health care services. The manuscript management system is completely online and includes a very quick and fair peer-review system. Visit http://www.dovepress.com/testimonials.php to read real quotes from published authors.

Submit your manuscript here: http://www.dovepress.com/advances-in-medical-education-and-practice-journal 